\title{
A Method for Understanding Customer Demands based on Extended Eco-VA
}

\author{
Kouji KIMITA ${ }^{1}$, Yoshiki SHIMOMURA ${ }^{2}$, Tomohiko SAKAO ${ }^{3}$ \\ ${ }^{1}$ Depertment of System Design, Tokyo Metropolitan University, Asahigaoka 6-6, Hino-shi, Tokyo 191-0065, Japan, \\ kimita-kouji@ed.tmu.ac.jp \\ ${ }^{2}$ Depertment of System Design, Tokyo Metropolitan University, yoshiki-shimomura@center.tmu.ac.jp \\ ${ }^{3}$ Mitsubishi Research Institute, Inc., sakao@mri.co.jp
}

\begin{abstract}
:
A sustainable society requires that products be environmentally friendly and conform to the market needs. According to this background, a tool named Extended Eco-Value Analysis has been developed by improving existing Eco-Value Analysis that allows product developers to analyze the functions of a product from economic costs, customers' importance, and environmental impacts. However, a result obtained from the application of this Extended Eco-VA is open to discussion. Therefore, this paper proposes a new method to obtain more accurate customer requirements. Furthermore, the authors improve the product evaluation criterion that is adopted in Eco-VA by considering the above method.
\end{abstract}

Keywords: Environment Conscious Design, Eco-Value Analysis, Customer Requirement Design Support, Service Modeling

\section{Introduction}

Although a number of eco-designed products have been released in the market, only a few have succeeded in incorporating customer needs effectively. Consequently, customers, at present, do not necessarily accept all eco-designed products. Hence, a sustainable society requires that products be environmentally friendly and conform to the market needs.

A tool named Extended Eco-Value Analysis (Extended Eco-VA) has been developed to meet such a need [1]. Extended Eco-VA is an improvement of Eco-Value Analysis (Eco-VA) [2], which allows product developers to analyze the functions of a product from the viewpoints of economic costs, customers' importance, and environmental impacts. To be concrete, first, the modeling method of Service Engineering (SE) [3] is adopted. Second, conjoint analysis [4] and analytic hierarchy process (AHP) [5] are applied to end users' evaluations. However, a result, especially the one related to customers' importance, obtained from the application of Extended Eco-VA is open to discussion.

According to this background, this study examines the validity of the result obtained from the application and modifies the questionnaire method in the first place. Then, the authors propose a classification of customers' requirements to obtain more accurate customer requirements. Furthermore, the authors improve the product evaluation criterion that is adopted in Eco-VA by considering the above classification.

\section{Existing Methods}

\subsection{Eco-VA}

Eco-VA is an improvement of the traditional value analysis (VA) [6]. While VA evaluates product value by quantifying a function over its economic cost, Eco-VA evaluates a function from the viewpoints of customers' importance, economic costs, and environmental impact. As shown in Figure 1, the three types of viewpoint have trade-off relationship among themselves.

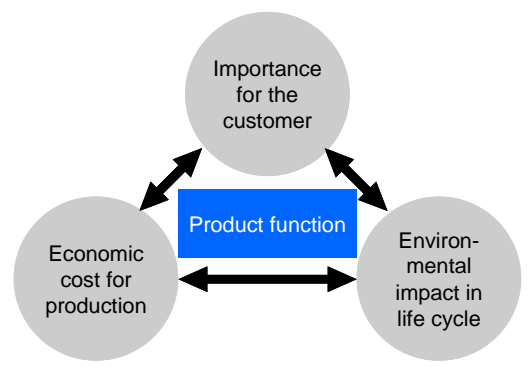

Figure 1: The three aspects of a function in Eco-VA [2]

According to the results, strategies for each function are presented as shown in Table 1. These strategies are suggested based on whether the product developer should realize a function, leave it out, or realize it after an improvement.

Table 1: Strategies for each function [2].

\begin{tabular}{|l|c|c|l|l|}
\hline & $\begin{array}{l}\text { Customer } \\
\text { import. }\end{array}$ & $\begin{array}{l}\text { Environm. } \\
\text { impacts }\end{array}$ & $\begin{array}{l}\text { Production } \\
\text { costs }\end{array}$ & Strategy \\
\hline C3 & High & High & High & $\begin{array}{l}\text { realize function and } \\
\text { reduce env. imp. and costs }\end{array}$ \\
\hline C1 & High & High & Low & $\begin{array}{l}\text { realize function and } \\
\text { reduce env. impacts }\end{array}$ \\
\hline A3 & High & Low & High & $\begin{array}{l}\text { realize function and } \\
\text { reduce production costs }\end{array}$ \\
\hline A1 & High & Low & Low & realize function \\
\hline D4 & Low & High & High & leave out function \\
\hline D2 & Low & High & Low & leave out function \\
\hline B4 & Low & Low & High & leave out function \\
\hline B2 & Low & Low & Low & no recommendation \\
\hline
\end{tabular}

Depends on the willingness to pay for the function 


\subsection{Service Engineering}

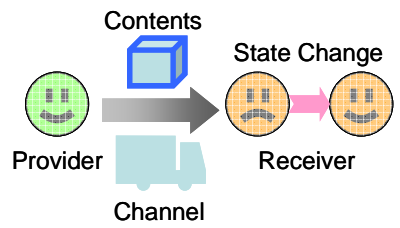

Figure 2: Definition of service [3].

$\mathrm{SE}$ is a new engineering discipline to increase the value of artifacts and decrease the load on the environment by reasons of focusing on service. For the purpose of SE, service is defined as an activity between a service provider and a service receiver to change the state of the receiver. A service is considered to be the delivery of "service contents" through "service channels," as shown in Figure 2. Service contents are materials, energy, or information that directly change the receiver's state. Service channels transfer, amplify, and control service contents.

According to this definition of service, the design of services depends on the change in a receiver's state. Therefore, it is necessary to find a method for expressing changes of the receiver's state. The states of service receivers are parameterized as follows: A receiver has a set of receiver state parameters (RSPs). On the other hand, in Service Engineering, a model named view model has been defined to describe the functional realization structure for changing a single RSP. A view model represents the multiple relationships among the physical/non-physical elements of the service: an RSP, service contents, and service channels. In addition, service contents and service channels are generally comprised of various functions. Thus, a view model works as a bridge between an RSP and the functions to change this RSP (see Figure 3.)

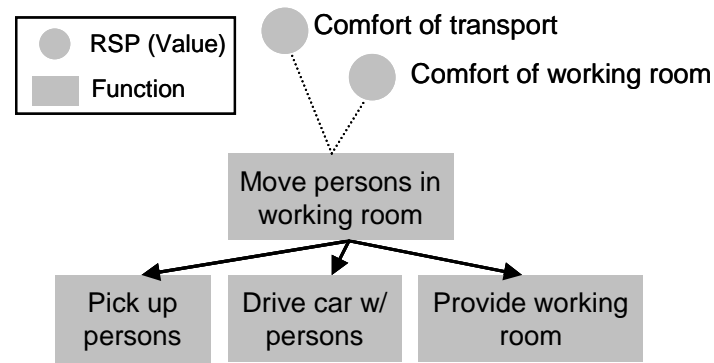

Figure 3: View Model [3].

\subsection{Extended Eco-Value Analysis}

Due to the characteristics of VA, Eco-VA has the following possible improvements. It is difficult to obtain accurate customer requirements of products using the original Eco-VA method. Since the benefits for customers are expressed in terms of functions, it is difficult to quantify customer importance of a function from the viewpoint of customers. Further, there is no established questionnaire method in Eco-VA.

In order to improve this limitation of the original Eco-VA method, a new method known as Extended Eco-VA was proposed. The main improvements in
Extended Eco-VA were as follows. First, the modeling method of SE was adopted. A function that had been used to represent value was replaced with RSP, which was used by designers to represent benefits or costs in SE. Second, conjoint analysis and AHP were also applied to end users' evaluations.

\section{The Presented Method}

In previous studies, Extended Eco-VA was applied to a food processing machine. A food processor is a machine that is used to cut, mix, or grind food in a shorter period of time at home. Further, by exchanging partial devices, it can be used for producing minced meat/fish, sliced vegetables, fruit juice, or leaven for bread.

However, its result was open to discussion. For example, this result showed that the main functions of the food processing machine (e.g., cutting, mixing, and grinding functions) were less important than other functions (e.g., economic cost and safety).

In order to solve this contradiction, the authors propose a method to obtain more accurate customer requirements with the classification of RSPs. By considering the above classification of RSPs, the authors improve the evaluation criterion that is adopted in Eco-VA.

\subsection{Classification of RSPs}

(1) Instrumental demand and Expressive demand

According to J. E. Swan and L. J. Combs, a product has two kinds of functions: instrumental performance and expressive performance [7]. In instrumental performance, the customer becomes more dissatisfied when the product is less functional, but his/her satisfaction never rises above neutral regardless of how functional the product becomes (see Figure 4 (a)). On the other hand, in expressive performance, the customer becomes more satisfied when the product is more functional but is not dissatisfied even when the product is less functional (see Figure 4 (b)).
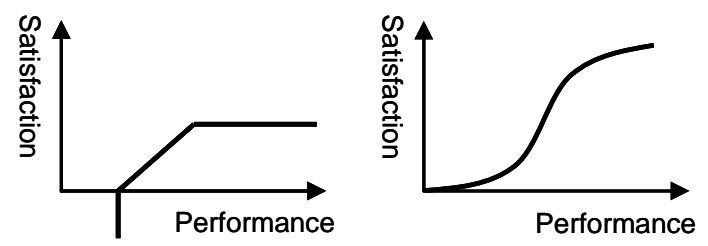

(a) Instrumental performance (b) Expressive performance Figure 4: Classification of functions.

This study classifies customer demands into "instrumental demand" and "expressive demand" based on the above classification of functions. With regard to instrumental demand, customers are certain that such a demand will be satisfied. In other words, if the performance of products or services is below customer expectations, then it will lead to dissatisfaction. Instrumental demand even motivates customers to purchase products or services. On the other hand, with 
respect to expressive demand, customers are not dissatisfied when products or services do not fulfill the demand but are more satisfied when they do fulfill the demand to a large extent.

In general, the classification of instrumental and expressive demands does not depend on products or services but on customers. Take automobiles for example. Customers who use automobiles for transportation believe that the styling of automobiles is not an end but an expressive demand. On the other hand, customers who possess automobiles as a means of self-expression consider styling as one of the ends, that is, an instrumental demand.

\section{(2) A demand as differentiation factor}

In addition, the authors assume that customer demand differentiates products and services in the market. This customer demand is that a customer focuses on when he/she compares several products or services. In other words, by fulfilling this customer demand, product or service developers can increase the market competitiveness of that product or service.

The customer demands that are the end of using a product or a service do not always generally correspond to the demands that are focused on by a customer when he/she compares several products or services. In other words, instrumental demand, which is the end of using products or services, does not necessarily correspond with the customer demand as differentiation factor. As an example, many people use mobile phones as a communication tool. In other words, the end of using a mobile phone is the communication function. If, however, a customer purchases a mobile phone, he/she shows an interest in additional functions, styling, etc. Then, there are some cases wherein customers do not consider instrumental demand while comparing a product with several products/services. Figure 5 shows the phase relationship of instrumental demands, expressive demands, and customer demands as differentiation factor.

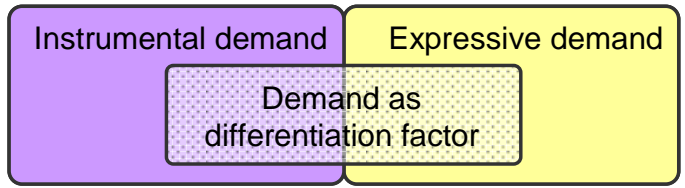

Figure 5: Phase relationship of instrumental demand, expressive demand, and customer demands as differentiation factor.

\section{(3) Value and Cost}

RSP is also classified into value and cost. While value indicates a benefit required by customers, cost implies a disbenefit to customers and indicates not only a monetary cost but also physical/mental affliction. In general, the classification of value and cost does not depend on products or services but on customers. Therefore, product or service developers can obtain customer demands more correctly by classifying RSPs into value and cost.

\subsection{Presentation of Design Strategies}

Reflecting the above classifications of RSPs in the evaluation criterion that is adopted in Eco-VA, the authors propose a new product evaluation criterion (see Table 2). This study evaluates RSPs, which express customer demands in SE, from the viewpoints of economic costs, customers' importance, and environmental impacts. The result reveals that the recommendations of strategies for each RSP are given. According to these recommendations for each RSP and the relationships among RSPs and functions described in a view model, product and service developers would be able to improve the functions that realize the significant RSP. The strategies shown in Table 2 can be explained in detail as follows:

Table 2: Design Strategies.

\begin{tabular}{|c|c|c|c|c|c|c|}
\hline & \multicolumn{3}{|c|}{ Customer importance } & \multirow[b]{2}{*}{$\begin{array}{c}\text { Env. } \\
\text { impacts }\end{array}$} & \multirow[b]{2}{*}{$\begin{array}{l}\text { Pro. } \\
\text { costs }\end{array}$} & \multirow[b]{2}{*}{ Strategy } \\
\hline & $\begin{array}{c}\text { Value } \\
\text { or } \\
\text { Cost } \\
\end{array}$ & \begin{tabular}{|c|}
$\begin{array}{c}\text { Type } \\
\text { of } \\
\text { Demand }\end{array}$ \\
\end{tabular} & Differentiation & & & \\
\hline R1 & \multirow{16}{*}{ Value } & \multirow{8}{*}{ Instrumental } & \multirow{4}{*}{ High } & High & High & $\mathrm{A}^{++} \mathrm{B} \mathrm{C}$ \\
\hline $\mathrm{R} 2$ & & & & High & Low & $\mathrm{A}^{++} \mathrm{B}$ \\
\hline R3 & & & & Low & High & $\begin{array}{ll}A^{++} & C\end{array}$ \\
\hline R4 & & & & Low & Low & $\overline{A^{++}}$ \\
\hline $\mathrm{R} 5$ & & & \multirow{4}{*}{ Low } & High & High & $\mathrm{A}^{+} \mathrm{B} \mathrm{C}$ \\
\hline $\mathrm{R} 6$ & & & & High & Low & $A^{+} B$ \\
\hline R7 & & & & Low & High & $\mathrm{A}^{+} \quad \mathrm{C}$ \\
\hline R8 & & & & Low & Low & $\mathrm{A}^{+}$ \\
\hline $\mathrm{R} 9$ & & \multirow{8}{*}{ Expressive } & \multirow{4}{*}{ High } & High & High & A $B$ C \\
\hline $\mathrm{R} 10$ & & & & High & Low & $A B$ \\
\hline R11 & & & & Low & High & $\begin{array}{ll}\mathrm{A} & \mathrm{C} \\
\end{array}$ \\
\hline $\mathrm{R} 12$ & & & & Low & Low & $A$ \\
\hline $\mathrm{R} 13$ & & & \multirow{4}{*}{ Low } & High & High & leave out \\
\hline R14 & & & & High & Low & leave out \\
\hline R15 & & & & Low & High & leave out \\
\hline R16 & & & & Low & Low & - \\
\hline R17 & \multirow{9}{*}{ Cost } & Instrumental & - & - & - & - \\
\hline R18 & & \multirow{8}{*}{ Expressive } & \multirow{4}{*}{ High } & High & High & A $\quad B \quad C$ \\
\hline $\mathrm{R} 19$ & & & & High & Low & A $B$ \\
\hline $\mathrm{R} 20$ & & & & Low & High & $\begin{array}{ll}A & C \\
\end{array}$ \\
\hline R21 & & & & Low & Low & $\mathrm{A}$ \\
\hline $\mathrm{R} 22$ & & & \multirow{4}{*}{ Low } & High & High & leave out \\
\hline $\mathrm{R} 23$ & & & & High & Low & leave out \\
\hline R24 & & & & Low & High & leave out \\
\hline R25 & & & & Low & Low & - \\
\hline R26 & Other & - & - & - & - & - \\
\hline
\end{tabular}

$\mathrm{A}^{++}$: Not below customer expectations and fulfill to a large extent

$\mathrm{A}^{+}$: Not below customer expectations

A: Fulfill to a large extent

B: Reduce environmental impacts

C: Reduce economic costs

- The RSP that is classified into category R1-R8 (instrumental demand and value) makes customers dissatisfied if it is below customer expectations. Furthermore, if the importance of the RSP as differentiation factor is high (R1-R4), then the market competitiveness of products or services can 
be increased by fulfilling this RSP to a large extent. Thus, the improving strategy then is to be "Not below customer expectations and fulfill to a large extent."

- If the RSP is classified into category R5-R8 (instrumental demand, value and its importance as differentiation factor is low), then the improving strategy is to be "Not below customer expectations."

- The RSP that is classified into category R9-R16 (expressive demand and value) does not make customers dissatisfied even if a product or service is below customer expectations. Therefore, if its importance as differentiation factor is high (R9-R12), then the improving strategy is to "fulfill to a large extent."

- The RSP that is classified into category R13-R16 (expressive demand and value and whose importance as differentiation factor is low) does not make customers dissatisfied even if it is not fulfilled. Furthermore, the market competitiveness of products or services cannot be increased even if this RSP is fulfilled to a large extent. Therefore, if economic costs or environmental impacts are high, then the improving strategy is to "leave out." When both are low, there is no strategy.

- This study does not cover the RSP that is classified into category R17 (instrumental demand and cost). In general, cost, which is negative demand when customers use a product or a service, can not be the purpose of using products or service.

- If the RSP is classified into category R18-R21 (expressive demand and cost and if its importance as differentiation factor is high), then the improving strategy is to "fulfill to a large extent."

- If the RSP is classified into category R22-R25 (expressive demand and cost and if its importance as differentiation factor is low), then the improving strategy is to "leave out" only if economic costs or environmental impacts are high. If both are low, then there is no strategy.

- The RSP that is classified into category R26 (neither value nor cost) is not considered by customers. Hence, this study does not cover this RSP.

\section{Application}

Based on the above classifications of customer demands, the presented method was applied by considering the example of a food processor. This section explains the application that focuses only on customers' importance of the three viewpoints. Important benefits and costs corresponding to RSPs and the functions to realize these RSPs are shown in Figure 6.

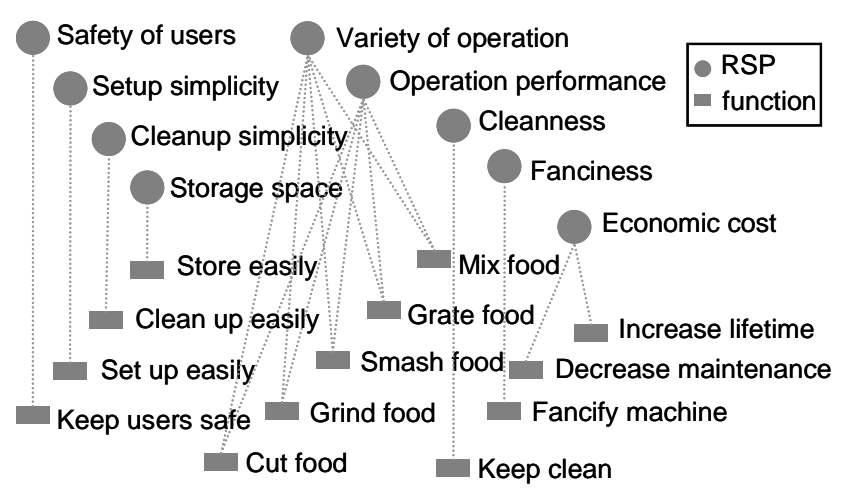

Figure 6: RSPs and functions of food processor.

Instrumental and expressive demands were classified by respondents from the RSP list of food processing machines. Value and cost were classified in the same manner. On the other hand, with respect to the differentiation factor, if customers were unable to determine relative merits in a certain factor, they could check another factor. Therefore, AHP was applied to quantify relative importance.

Table 3 shows the classification of instrumental and expressive demands obtained from two examinees. Examinee A was different from examinee B in terms of "Cleanness" and "Variety of operation"; while examinee A classified "Cleanness" as instrumental demand and "Variety of operation" as expressive demand, examinee B classified "Cleanness" as expressive demand and "Variety of operation" as instrumental demand.

Table3: Classification of Instrumental Demand or Expressive Demand.

\begin{tabular}{|c|l|l|}
\hline & \multicolumn{1}{|c|}{ Examinee A } & \multicolumn{1}{c|}{ Examinee B } \\
\hline $\begin{array}{c}\text { Instrumental } \\
\text { demand }\end{array}$ & Operation performance & Variety of operation \\
& Cleanness & Operation performance \\
\hline & Setup simplicity & Setup simplicity \\
& Variety of operation & Cleanness \\
Expressive & Cleanup simplicity & Cleanup simplicity \\
demand & Fanciness & Fanciness \\
& Economic cost & Economic cost \\
& Storage space & Storage space \\
& Safety of users & Safety of users \\
\hline
\end{tabular}

The figure 7 and figure 8 show the results of each respondent. Figure 7 was obtained from examinee A. The following are the items that indicated that importance of RSPs as differentiation factor was high: "Variety of operation," "Operation performance," "Cleanness," "Economic cost," and "Safety of users." From among these items, "Variety of operation," "Economic cost," and "Safety of users" were classified as expressive demand.

Figure 8 was obtained from examinee B. The following are the items that indicated that importance of RSPs as differentiation factor was high: "Variety of operation," "Operation performance," "Cleanness," "Economic cost," and "Safety of users." From among these items, "Cleanness," "Economic cost," and "Safety of users" were classified as expressive demand. 

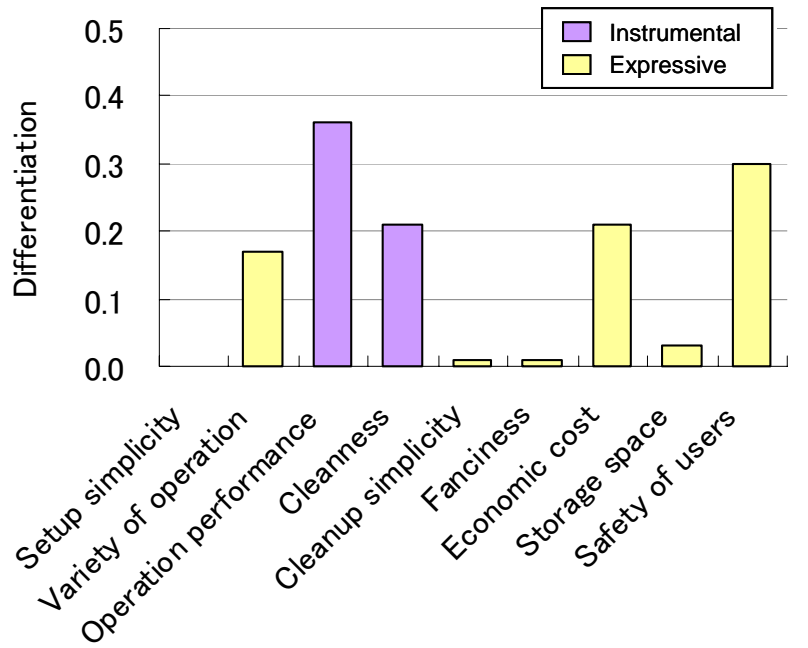

Figure 7: Importance of RSPs as differentiation factor obtained from examinee A.
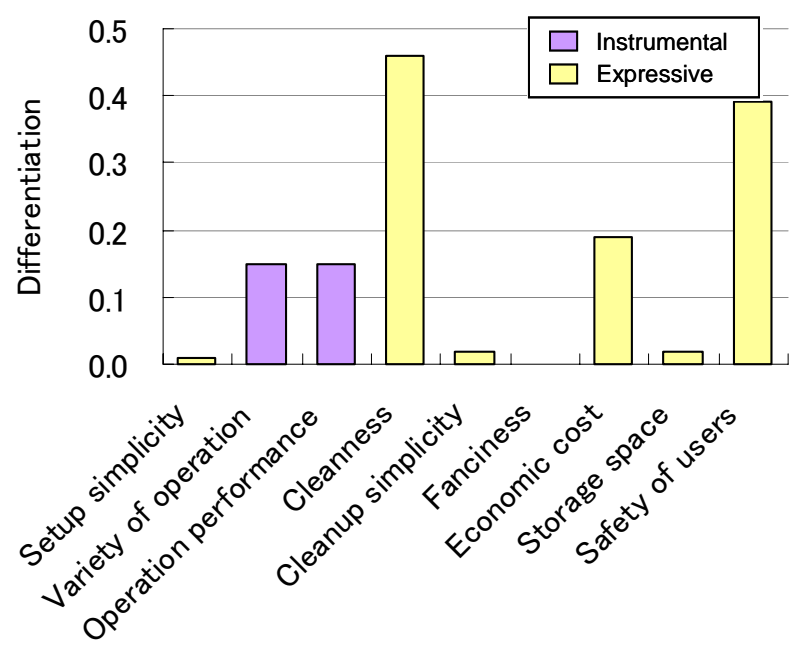

Figure 8: Importance of RSPs as differentiation factor obtained from examinee B.
Table 4 shows the classification of value and cost. Examinee A was different from examinee B in terms of "Cleanup simplicity" and "Storage space"; while examinee A classified "Cleanup simplicity" and "Storage space" as cost, examinee B classified both as other.

Table 4: Classification of Value and Cost.

\begin{tabular}{|c|l|l|}
\hline & \multicolumn{1}{|c|}{ Examinee A } & \multicolumn{1}{c|}{ Examinee B } \\
\hline Value & $\begin{array}{l}\text { Variety of operation } \\
\text { Operation performance } \\
\text { Cleanness } \\
\text { Safety of users }\end{array}$ & $\begin{array}{l}\text { Variety of operation } \\
\text { Operation performance } \\
\text { Cleanness } \\
\text { Safety of users }\end{array}$ \\
\hline Cost & $\begin{array}{l}\text { Cleanup simplicity } \\
\text { Economic cost } \\
\text { Storage space }\end{array}$ & Economic cost \\
\hline Other & $\begin{array}{l}\text { Setup simplicity } \\
\text { Fanciness }\end{array}$ & $\begin{array}{l}\text { Setup simplicity } \\
\text { Cleanup simplicity } \\
\text { Fanciness } \\
\text { Storage space }\end{array}$ \\
\hline
\end{tabular}

The analysis of each RSP from the viewpoints of economic costs and environmental burden was performed by calculating the production costs and environment impacts of realization structure that realize RSP. Environment impacts were obtained from Eco indicator 99 method [8]. Finally, some strategies based on the results of each examinee were generated according to Table 2, as shown in Tables 5 and 6 .

Table 5 shows the design strategy for examinee A. The design strategy includes the following: not below customer expectations, fulfill to a large extent, and reduce environmental impacts and production costs for "Operation performance" and not below customer expectations and fulfill to a large extent for "Cleanness."

Table 6 shows the design strategy for examinee B. The design strategy includes the following: not below customer expectations, fulfill to a large extent, and reduce environmental impacts and production costs for "Operation performance" and "Variety of operation" and fulfill to a large extent for "Cleanness" and "Safety of users.

Table 5: Design Strategies for examinee A.

\begin{tabular}{|c|c|c|c|c|c|c|c|}
\hline & \multicolumn{3}{|c|}{ Customer importance } & \multirow[b]{2}{*}{ Env. } & \multirow[b]{2}{*}{$\begin{array}{l}\text { Pro. } \\
\text { costs }\end{array}$} & \multirow[b]{2}{*}{ RSP } & \multirow[b]{2}{*}{ Strategy } \\
\hline & $\begin{array}{c}\text { Value } \\
\text { or } \\
\text { Cost } \\
\end{array}$ & \begin{tabular}{|c|}
$\begin{array}{c}\text { Type } \\
\text { of } \\
\text { Demand }\end{array}$ \\
\end{tabular} & Differentiator & & & & \\
\hline $\mathrm{R} 1$ & \multirow{4}{*}{ Value } & \multirow[t]{2}{*}{ Instrumental } & \multirow[t]{2}{*}{ High } & High & High & Operation performance & $\begin{array}{l}\text { Not below costomer expectations } \\
\text { Fulfill to a large extent } \\
\text { Reduce environmental impacts and production }\end{array}$ \\
\hline $\mathrm{R} 4$ & & & & Low & Low & Cleanness & $\begin{array}{l}\text { Not be below customers' expectation } \\
\text { Fulfill to a large extent }\end{array}$ \\
\hline $\mathrm{R} 9$ & & \multirow[t]{2}{*}{ Expressive } & \multirow[t]{2}{*}{ High } & High & High & Variety of operation & $\begin{array}{l}\text { Fulfill to a large extent } \\
\text { Reduce environmental impacts and production }\end{array}$ \\
\hline R12 & & & & Low & Low & Safety of users & Fulfill to a large extent \\
\hline R20 & \multirow{2}{*}{ Cost } & \multirow{2}{*}{ Expressive } & High & Low & High & Economic cost & $\begin{array}{l}\text { Fulfill to a large extent } \\
\text { Reduce production costs }\end{array}$ \\
\hline R25 & & & Low & Low & Low & $\begin{array}{l}\text { Cleanup simplicity } \\
\text { Storage space }\end{array}$ & No recommendation \\
\hline R26 & Other & - & - & - & - & $\begin{array}{l}\text { Setup simplicity } \\
\text { Fanciness }\end{array}$ & No recommendation \\
\hline
\end{tabular}


Table 6: Design Strategies for examinee B.

\begin{tabular}{|c|c|c|c|c|c|c|c|}
\hline & \multicolumn{3}{|c|}{ Customer importance } & \multirow[b]{2}{*}{$\begin{array}{l}\text { Env. } \\
\text { impacts }\end{array}$} & \multirow[b]{2}{*}{$\begin{array}{l}\text { Pro. } \\
\text { costs }\end{array}$} & \multirow[b]{2}{*}{ RSP } & \multirow[b]{2}{*}{ Strategy } \\
\hline & $\begin{array}{c}\text { Value } \\
\text { or } \\
\text { Cost } \\
\end{array}$ & \begin{tabular}{|c|}
$\begin{array}{c}\text { Type } \\
\text { of } \\
\text { Demand }\end{array}$ \\
\end{tabular} & Differentiator & & & & \\
\hline $\mathrm{R} 1$ & \multirow[t]{2}{*}{ Value } & Instrumental & High & High & High & $\begin{array}{l}\text { Variety of operation } \\
\text { Operation performance }\end{array}$ & $\begin{array}{l}\text { Not beLow customer expectations } \\
\text { Fulfill to a large extent } \\
\text { Reduce environmental impacts and production }\end{array}$ \\
\hline R12 & & Expressive & High & Low & Low & $\begin{array}{l}\text { Cleanness } \\
\text { Safety of users }\end{array}$ & Fulfill to a large extent \\
\hline R20 & Cost & Expressive & High & Low & High & Economic cost & \begin{tabular}{|l} 
Fulfill to a large extent \\
Reduce production costs
\end{tabular} \\
\hline R26 & Other & - & - & - & - & $\begin{array}{l}\text { Setup simplicity } \\
\text { Cleanup simplicity } \\
\text { Fanciness } \\
\text { Storage space }\end{array}$ & No recommendation \\
\hline
\end{tabular}

\section{Discussion}

This application was carried out according to the presented classification of RSPs. The result indicated that instrumental demand, which is the end of using a product or service, does not necessarily correspond to a demand as differentiation factor, which a customer focuses on when he/she compares several products or services. Furthermore, the result revealed that the classification of instrumental and expressive demands does not depend on products or services but on customers. The classification of value and cost also does not depend on products or services but on customers. Thus, the proposed method allows product developers to obtain more detailed information about customer requirements. In view of the presented classification of RSPs, the authors improve the evaluation criterion that is adopted in Eco-VA. Accordingly, the proposed method can suggest a detailed product design strategy for each RSP. This design strategy is, however, not for function but for RSP. To make product and service developers obtain more concrete design strategy, design strategy needs to be suggested for each function. On the other hand, in Service Engineering, a method is proposed; customer importance of each RSP is allocated to functions that realize the RSP by using AHP and Dematel method [9]. Based on the above method, the design strategy will be able to be suggested for each function of products or services.

In this application, two design strategies were proposed for each examinee and these two design strategies were quite different. In order to apply this proposed method to practical design, these different sets of design strategies should not be integrated in simple way. Because, it is difficuilt to increase the satisfaction of customers by adopting a compromise design solution . For instance, to solve this problem, methods of mass customization should be examined.

\section{Conclusion}

This paper proposed classifications of RSPs to obtain more detailed information about customer requirements, and improved the product evaluation criterion that is adopted in Eco-VA by considering the above classification of RSPs. Furthermore, the authors carried out the application to a food processing machine. As a result, a more detailed design strategy was suggested for RSPs based on the result obtained from this method. Future works include verifying proposed classifications of RSPs by applying additional examinations. Furthermore, the authors will establish a method to assist product and service developers to obtain more concrete design strategy.

\section{Acknowledgments}

The authors adopted the results from Life Cycle Assessment of the product carried out by Darmstadt University of Technology in Germany.

\section{Reference}

[1] Sakao, T., Oberender, C., Krone, N., Shimomura, Y., Birkhofer, H. and Reichi, H., 2006, Evaluating Customer Requirements in Eco-VA, In Proceedings of the 13th CIRP International Conference on Life Cycle Engineering -LCE2006-, pp.519-524.

[2] Oberender, C., Birkhofer, H., 2004, Designing Environmentally Friendly Products in Conformity with the Market - A Holistic Analysis of Product Characteristics-, International Congress and Exhibition Electronics Goes Green 2004+, pp. 481-486.

[3] Arai, T., Shimomura, Y., 2004, Proposal of Service CAD System -A Tool for Service Engineering-, Annals of the CIRP, 53/1, pp.397-400.

[4] Green, E., Srinivasan, V., 1978, Conjoint Analysis in Consumer Research: Issues and Outlook, Journal of Consumer Research, 5, pp.103-123.

[5] Saaty, L., 1980, The Analytic Hierarchy Process, McGraw-Hill.

[6] EN 12973: Value Management, 2002, Beuth.

[7] Swan, J., Combs, L., 1976, Product Performance and Consumer Satisfaction: A New Concept, Journal of Marketing, 41, pp.77-79.

[8] Goedkoop, M., Effting, S. and Collignon, M., 2000, The Eco-indicator 99: A damage oriented method for Life Cycle Impact Assessment, Manual for Designers.

[9] Fontela, E., Gabus, A., 1973, "DEMATEL Report, Analytical Methods", Battelle Geneva Research Centre. 